\title{
Pediatric Airway Emergency Referrals Requiring Surgical Management: A Five-Year Experience at King Abdulaziz University
}

\author{
Rafat S. Sindi, MD, F.E.B, Khalil S. Sendi, MD, Shatha M. Albokhari' ${ }^{1}$ MD, \\ Mahmood A. Alreefi, MD
}

Department of Otolaryngology and Head and Neck Surgery and 'Department of Pediatrics Faculty of Medicine, King Abdulaziz University, Jeddah, Saudi Arabia

\section{Correspondence}

Dr. Rafat S. Sindi

P.O. Box 80205, Jeddah 21589, Saudi Arabia

e.M: rafatsindi@yahoo.com

Submission: 18 Jan. 2015

Accepted: 3 Mar. 2015

\section{Citation}

Sindi RS, Sendi KS, Albokhari SM, Alreefi MA, Al Ghamdi AA, Safi MA. Pediatric airway emergency referrals requiring surgical management: A five-year experience at King Abdulaziz University. JKAU Med Sci 2015; 22 (2): 19-24. DOI: 10.4197/Med. 22.2.3

\begin{abstract}
Pediatric airway emergencies are uncommon, however they are challenging. This study aims to describe our experience in the surgical management of pediatric airway emergencies. This was a retrospective chart review of the medical records of pediatric patients at the Department of Otolaryngology and Head and Neck Surgery of King Abdulaziz University Hospital, between November 2008 and November 2013. We recorded the age, gender, cause of referral, diagnosis, genetic disorders, surgery performed, and the need for further surgical intervention. Data were analyzed using the Statistical Package for the Social Sciences. 37 patients were included with ages between 45 days and 10 years. In most cases, patients were referred for failed extubation, followed by stride; Laryngomalacia was the most frequently diagnosed condition. Less common diagnoses included presence of a thick mucus plug, nearly half of the referred patients had neurological disorders; $40.5 \%$ and $27.0 \%$ of the patients had respiratory, and cardiovascular disorders, respectively. Bronchoscopy was the most frequently performed surgery, followed by tracheostomy. Less than half of the patients (45.9\%) needed further surgical intervention. Pediatric airway emergencies referral is uncommon. Failure to extubate is the most common etiological factor and bronchoscopy is the most commonly performed procedure.
\end{abstract}

\section{Keywords}

Airway emergency; Bronchoscopy; Pediatrics; Surgical management; Tracheostomy

\section{Introduction}

ediatric emergencies account for only $2-10 \%$ of all medical emergencies ${ }^{[1]}$. In addition, pediatric airway disorders are, fortunately, not commonly encountered. The management of pediatric airway disorders is, however, challenging due to the anatomic differences between children and adults, which predispose children to acute airway compromise ${ }^{[2]}$. Thus, pediatric cases of airway disorder that are referred to an otolaryngologist on an emergency basis indicate the seriousness of the condition and the need for fast intervention, since poor or inadequate management might lead to an unfavorable outcome, including serious injury and death. 
Pediatricians should be capable of recognizing an obstructive respiratory emergency, because prompt recognition of an airway compromise and appropriate, timely intervention are necessary to achieve the best possible outcome ${ }^{[2]}$. In general, if rapid reversal of an impending airway complication is impossible, then the best approach is to temporarily secure the airways. However, when an unexpectedly difficult airway obstruction occurs in a child, a pediatrician should rapidly refer the patient for specialized care; it is critical to not persist with repeated attempts since this can cause trauma to the upper airway, edema, and bleeding ${ }^{[3]}$.

Emergency airway referrals to the otorhinolaryngology departmentare common. Surgical management options are enormous and choosing the correct one can benefit the patient by preventing the occurrence of life-threatening complications. King Abdulaziz University Hospital (KAUH) manages many cases of pediatric airway emergencies, and it is important to have knowledge of how these cases are managed, as it will help to establish an idea of the common pathologies that are routinely encountered as well as their outcomes. Thus, the aim of this study is to describe our experience in the surgical management of pediatric airway emergencies.

\section{Methods}

A retrospective chart review was performed of the medical records of pediatric patients who were followed up and treated at the Department of Otolaryngology and Head and Neck Surgery of KAUH between November 2008 and November 2013. We included all children who were referred from the Pediatric department for surgical management of an airway emergency. All non-pediatric cases of airway emergencies and pediatric airway emergencies that required non-surgical treatment were excluded. The Biomedical Ethics Committee of King Abdulaziz University granted approval to conduct the study.

For all patients included in the study, the following data were recorded: Age, gender, cause of referral, confirmed diagnosis, genetic and other systematic disorders, prematurity status, type of surgery performed, and the need for further surgical intervention.

There is no fixed protocol for the management of pediatric airway emergencies at our department, as treatment depends on several factors, including the etiology of the airway disorder, the patient's status, and the presence of other co-morbidities.

\section{Statistical Analysis}

The data were analyzed using the IBM SPSS Statistics for Windows, Version 20 (IBM Corp., Armonk, NY USA). Descriptive statistics were calculated for all variables. Results are expressed in frequency (percent).

\section{Results}

We included 37 patients with ages between 45 days and 10 years. Over half of the referred cases were infants less than six months old. Males comprised $59.5 \%$ of the sample (Table 1 ).

In most cases patients were referred for failed extubation, followed by stridor and respiratory distress (Table 2). Laryngomalacia was the most frequently diagnosed condition. Less common diagnoses included the presence of a thick mucus plug, tuberculosis, supraglottic adhesions, and bronchial foreign body.

Nearly half of the referred patients had neurological disorders (Table 3); $40.5 \%$ and $27.0 \%$ of the patients had

Table 1. Demographic characteristics of the population.

\begin{tabular}{|c|c|}
\hline \multicolumn{1}{|c|}{ Variables } & Frequency (Percent) \\
\hline Gender & $22(59.50 \%)$ \\
\hline Male & $15(40.50 \%)$ \\
\hline Female & \\
\hline Age Group & $20(54.10 \%)$ \\
\hline 0-6 months & $4(10.80 \%)$ \\
\hline 6 months - 1 year & $11(29.70 \%)$ \\
\hline 1-5 years & $2(5.40 \%)$ \\
\hline 5-10 years
\end{tabular}

Table 2. Surgical characteristics of the patients.

\begin{tabular}{|c|c|}
\hline \multicolumn{1}{|c|}{ Variables } & Frequency (Percent) \\
\hline Surgeries performed & $22(59.50 \%)$ \\
\hline Bronchoscopy & $15(40.50 \%)$ \\
\hline Tracheostomy & $2(5.40 \%)$ \\
\hline Epiglottopexy & $1(2.70 \%)$ \\
\hline Airway Stenting & $1(2.70 \%)$ \\
\hline Broncho-alveolar Lavage & $1(2.70 \%)$ \\
\hline Partial Glossectomy & $1(2.70 \%)$ \\
\hline Choanal Atresia Repair & $3(8.10 \%)$ \\
\hline Other & $17(45.90 \%)$ \\
\hline Further surgical intervention needed & $20(54.10 \%)$ \\
\hline Yes & \\
\hline No & $9(52.90 \%)$ \\
\hline Number of further interventions required & $4(23.50 \%)$ \\
\hline 1 & $1(5.90 \%)$ \\
\hline 2 & $3(17.60 \%)$ \\
\hline 3 & \\
\hline 4 &
\end{tabular}


Table 3. Clinical characteristics of the patients.

\begin{tabular}{|c|c|}
\hline Variables & Frequency (Percent) \\
\hline \multicolumn{2}{|l|}{ Reason for referral } \\
\hline Stridor & $10(27.00 \%)$ \\
\hline Failed Extubation & $24(64.90 \%)$ \\
\hline Respiratory Distress & $3(8.10 \%)$ \\
\hline \multicolumn{2}{|l|}{ Confirmed diagnosis } \\
\hline Subglottic Stenosis & $6(16.20 \%)$ \\
\hline Laryngomalacia & $10(27.00 \%)$ \\
\hline Tracheomalacia & $4(10.80 \%)$ \\
\hline Bronchial Stenosis & $2(5.40 \%)$ \\
\hline Choanal Atresia & $4(10.80 \%)$ \\
\hline Vocal Cord Paralysis & $4(10.80 \%)$ \\
\hline Supraglottic Adhesions & $1(2.70 \%)$ \\
\hline Bronchial Foreign Body & $1(2.70 \%)$ \\
\hline Macroglossia & $2(5.40 \%)$ \\
\hline Deviated Nasal Septum & $2(5.40 \%)$ \\
\hline Thick Mucus Plus & $1(2.70 \%)$ \\
\hline Tuberculosis & $1(2.70 \%)$ \\
\hline 0ther & $17(45.90 \%)$ \\
\hline \multicolumn{2}{|l|}{ Disorders } \\
\hline Cardiovascular & $10(27.00 \%)$ \\
\hline Respiratory & $15(40.50 \%)$ \\
\hline Gastrointestinal & $7(18.90 \%)$ \\
\hline Genitourinary & $3(8.10 \%)$ \\
\hline Hematological & $2(5.40 \%)$ \\
\hline Musculoskeletal & $1(2.70 \%)$ \\
\hline Endocrine & $4(10.80 \%)$ \\
\hline Neurological & $19(51.40 \%)$ \\
\hline
\end{tabular}

respiratory and cardiovascular disorders, respectively. Premature patients constituted less than one quarter of the sample. Nearly a third of the patients $(n=12$, $32.4 \%)$ had genetic disorders, four of $(33.3 \%)$ whom had Down's syndrome.

Bronchoscopy was the most frequently performed surgery, followed by tracheostomy (Table 3). Almost half $(45.9 \%)$ of the patients needed further surgical intervention. Of these patients, $52.9 \%$ needed one more surgery, $23.5 \%$ needed two more, $5.9 \%$ needed three more, and $17.6 \%$ needed four more surgeries.

\section{Discussion}

This retrospective chart review sought to describe our experience with the management of pediatric airway emergencies at the Otorhinolaryngology Department of KAUH. Our analysis shows that most cases of pediatric respiratory emergency were referred for failed extubation, followed by stridor, and respiratory distress.

The frequency of extubation failure in our study was $64.9 \%$. The rates of extubation failure vary slightly in the literature. According to one report ${ }^{[4]}$, extubation failure occurs in $10 \%$ to $20 \%$ of patients, and it is associated with adverse outcomes, including mortality rates of up to $25-50 \%$. In another report ${ }^{[5]}$, the authors reported that the rate of extubation failure varies from $2 \%$ to $20 \%$ depending on the patient population under consideration. However, the differences observed in the extubation failure rates may be explained by the authors' definition of extubation failure. While we considered extubation failure to mean the failure to be extubated, the other authors defined extubation failure as the need to reintubate and mechanically ventilate the patient after prior successful weaning from respiratory ventilation and extubation.

Stridor was the second most common reason for referral in our study, reported in $27.0 \%$ of the cases. In the intensive care setting, the prevalence of post-extubation stridor ranges between 6 and 37\% ${ }^{[6]}$, and factors such as female gender, elevated Acute Physiologic and Chronic Health Evaluation II score, low Glasgow Coma Scale score, and long intubation period have been correlated with the occurrence of post extubation stridor ${ }^{[7-10]}$.

Respiratory distress, which was the main reason for referral in $8.1 \%$ of the cases in our study, occurs relatively infrequently in the pediatric intensive care unit (PICU). The reported incidence of acute respiratory distress syndrome in patients admitted to the PICU varies between $1.4 \%$ and $3.9 \%^{[11-14]}$. However, the mortality rates associated with acute respiratory distress syndrome vary considerably between studies, with rates reported at $26 \%$ to as high as $61 \%{ }^{[12-17]}$.

Although our study highlights the most common causes of pediatric airway referrals at our institution, the findings must be interpreted in the light of its limitations. First, our study was limited by its small size. This precluded us from making relevant comparisons with the findings of other studies. Second, the lack of detailed computerized notes post-surgery did not permit us to record additional details regarding patients' recovery after surgical intervention. In addition, the exact cause of extubation failure was not documented in patients' files.

In the current study, bronchoscopy was the most frequently performed surgery, followed by tracheostomy.

The average length of stay was two weeks and $12.5 \%$ stayed for two months post procedures. Regarding other issues related to the original diagnosis 
of the patients included in the study $6.25 \%$ had tracheostomy malfunction, $6.25 \%$ complicated by emphysema ended by removal of the tracheostomy, $12.5 \%$ were complicated by chest infection (gram negative bacilli in respiratory culture) in which one was admitted to PICU, mortality was reported in $25 \%$ due to unknown causes (lack of documentation) and 50\% of the patients lost follow up with both pediatric and ENT teams.

\section{Conclusion}

Pediatric airway emergencies referral is uncommon. Failure to extubate is the most common etiological factor and bronchoscopy is the most commonly performed procedure. The majority of these patients are premature, suffer other systemic disorders and usually required multiple surgeries during the follow-up period.

\section{Conflict of Interest}

The authors have no conflict of interest.

\section{Disclosure}

None of the authors received any type of commercial support either in forms of compensation or financial for this study. They have no financial interest in any of the products or devices, or drugs mentioned in this article.

\section{Ethical Approval}

Obtained.

\section{References}

[1] Bernhard M1, Hilger $T$, Sikinger $M$, Hainer C, Haag S, Streitberger K, Martin E, Gries A. [Spectrum of patients in prehospital emergency services. What has changed over the last 20 years?]. Anaesthesist 2006; 55(11): 1157-1165.

[2] Rotta AT, Wiryawan B. Respiratory emergencies in children. Respir Care 2003; 48(3): 248-260

[3] Stackhouse RA, Infasino A. Airway Management. In: Basics of Anesthesia. 6th edn. Miller RD, Pardo M. eds Philadelphia: Elsevier. 219-251.

[4] Thille AW, Richard JC, Brochard L. The decision to extubate in the intensive care unit. Am J Respir Crit Care Med 2013; 187(12): 1294-1302.

[5] Epstein SK. Endotracheal extubation. Respir Care Clin N Am 2000; 6(2): 321-360.

[6] Lee $\mathrm{CH}$, Peng MJ, Wu CL. Dexamethasone to prevent postextubation airway obstruction in adults: a prospective, randomized, double-blind, placebo-controlled study. Crit Care 2007; 11(4): R72.

[7] Jaber S, Chanques G, Matecki S, Ramonatxo M, Vergne C, Souche B, Perrigualt PF, Eledjam JJ. Postextubation stridor in intensive care unit patients. Risk factors evaluation and importance of the cuff-leak test. Intensive Care Med 2003; 29(1): 69-74.

[8] Erginel S, Ucgun I, Yildirim H, Metintas M, Parspour S. High body mass index and long duration of intubation increase postextubation stridor in patients with mechanical ventilation. Tohoku J Exp Med 2005; 207(2): 125-132.

[9] Cheng KC, Hou CC, Huang HC, Lin SC, Zhang H: Intravenous injection of methylprednisolone reduces the incidence of postextubation stridor in intensive care unit patients. Crit Care Med 2006; 34(5): 1345-1350.

[10] François B, Bellissant E, Gissot V, Desachy A, Normand S, Boulain T, Brenet O, Preux PM, Vignon P; Association des Réanimateurs du Centre-Ouest (ARCO). 12-h pretreatment with methylprednisolone versus placebo for prevention of postextubation laryngeal oedema: a randomised doubleblind trial. Lancet 2007; 369(9567): 1083-1089.

[11] Bindl L, Dresbach K, Lentze MJ. Incidence of acute respiratory distress syndrome in German children and adolescents: a population-based study. Crit Care Med 2005; 33(1): 209-212.

[12] Yu WL, Lu ZJ, Wang Y, Shi LP, Kuang FW, Qian SY, Zeng QY, Xie MH, Zhang GY, Zhuang DY, Fan XM, Sun B Collaborative Study Group of Pediatric Respiratory Failure. The epidemiology of acute respiratory distress syndrome in pediatric intensive care units in China. Intensive Care Med 2009; 35(1): 136-143.

[13] Kneyber MC, Brouwers AG, Caris JA, Chedamni S, Plötz FB. Acute respiratory distress syndrome: is it underrecognized in the pediatric intensive care unit? Intensive Care Med 2008; 34(4): 751-754.

[14] López-Fernández Y, Azagra AM, de la Oliva P, Modesto V Sánchez Jl, Parrilla J, Arroyo MJ, Reyes SB, Pons-Ódena M, López-Herce J, Fernández RL, Kacmarek RM, Villar J; Pediatric Acute Lung Injury Epidemiology and Natural History (PEDALIEN) Network. Pediatric Acute Lung Injury Epidemiology and Natural History study: Incidence and outcome of the acute respiratory distress syndrome in children. Crit Care Med 2012; 40(12): 3238-3245.

[15] Farias JA, Frutos F, Esteban A, Flores JC, Retta A, Baltodano A, Alía I, Hatzis T, Olazarri F, Petros A, Johnson M. What is the daily practice of mechanical ventilation in pediatric intensive care units? A multicenter study. Intensive Care Med 2004; 30(5): 918-925

[16] Flori HR, Glidden DV, Rutherford GW, Matthay MA. Pediatric acute lung injury: prospective evaluation of risk factors associated with mortality. Am J Respir Crit Care Med 2005; 171(9): 995-1001.

[17] Erickson S, Schibler A, Numa A, Nuthall G, Yung M, Pascoe E, Wilkins B; Paediatric Study Group; Australian and New 
Pediatric Airway Emergency Referrals Requiring Surgical Management: A Five-Year Experience at King Abdulaziz University R.S. Sindi et al.

Zealand Intensive Care Society. Acute lung injury in pediatric intensive care in Australia and New Zealand-a prospective, multicenter, observational study. Pediatr Crit Care Med 2007; 8(4): 317-323. 


\title{
إحالة حالات طوارئ مجرى التنفس لاى الأطفال التي تحتاج لتدخل جراحي: خلاصة خبرة خمس سنين بمستشفى جامعة الملك عبدالعزيز
}

\author{
رأفت صدقة سندي، وخليل صدقة سندي، وشذا محمد البخاري'، ومحمود عبدالله الريفي \\ قسم الانف والانن والحنجرة والرأس والعنق، و 'قسم الاطفال، كلية الطب، جامعة الدلك عبدالعزيز \\ جدة - المدلكة العربية السعودية
}

الصستخلص. طو ارئ مجرى التنفس لاى الأطفال ليست واسعة الانتشار، ولكنها تتكل تحديًا لعلاجها. هذه الدر اسة تهدف لثرح خبرتنا في التدخل الجراحي لها. لذللك قمنا بمر اجعة الملفات الطبية للأطفال الذين تمت إحالتهم وعلاجهم بالتنخل

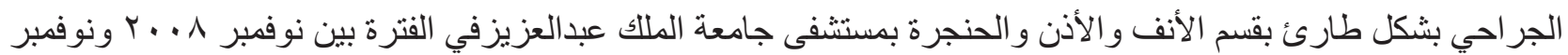

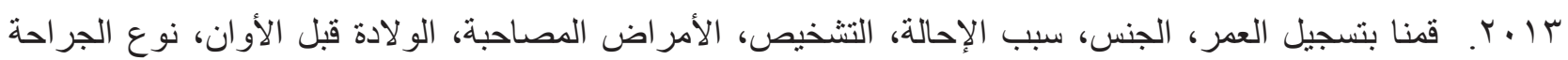
و الحاجة لتدخل جراحي آخر لاحقاً، ثم قمنا بتحليل النتائج باستخدام برنامج SPSS. البحث شمل Vr طفلا نراوحت أعمار هم بين 0؛ يوم إلى • ( سنين. في أغلب الحالات ، تمت إحالة المريض بسبب فنشل إخر اج أنبوب داخل الرغامى، وتبعه الصفير

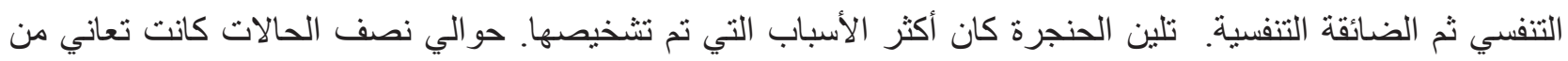

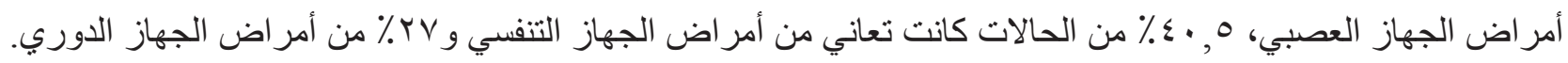

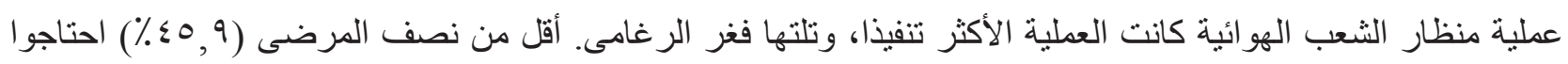
لتنخل جراحي لاحق.الاستتناج: فثل إخر اج أنبوب داخل الرغامى هو المسبب الأول لإحالة حالات الأطفال كطوارئ مجرى التنفس، كما أن العطلية الأكثر تطبيقا كانت منظار الثعب الهوائية والمرض الأكثر تشخيصا هو تلين الحنجرة. 